\section{Por que ler Jessé Souza?}

\section{Why to read Jessé Souza?}

SOUZA, Jessé. A elite do atraso: da escravidão à Bolsonaro. Edição revista e ampliada, Rio de Janeiro, Estação Brasil, 2019. 272 pp.

\section{José Fernando Andrade Costa}

(iD) https://orcid.org/0000-0002-5677-0093

Universidade Estadual de Feira de Santana, UEFS, Feira de Santana - BA, Brasil. E-mail: jfacosta@uefs.br

DOI: $10.1590 / 3510205 / 2020$

Nos últimos anos, o sociólogo brasileiro Jessé Souza tem protagonizado uma série de polêmicas, dentro e fora do campo acadêmico. Com um ritmo acelerado de publicaçóes, e dono de um estilo provocativo de argumentação, Souza divide opinióes entre especialistas e leigos. A publicação de $A$ elite do atraso: da escravidão à Bolsonaro resume bem o ambicioso projeto do autor, nas últimas duas décadas, de oferecer uma nova interpretação da realidade social brasileira. Se o ponto de largada foi um amplo programa de pesquisa teórica e empírica sobre as classes sociais no Brasil (Souza, 2000, 2003, 2009, 2010), o ponto de chegada tem sido uma intensa disputa de narrativa (Souza, 2015, 2016).

O livro é uma reedição atualizada da versão publicada pouco mais de um ano antes ${ }^{1}$. Nesse novo livro, Souza sistematiza as ideias desenvolvidas em seus escritos anteriores, cujo cerne é a crítica do que ele denomina "ciência social conservadora", ao reafirmar a tese de que a interpretação sociológica dominante sobre o Brasil, até agora, tem servido à reprodução dos interesses das elites. Desde a publicação de $A$ modernização seletiva e $A$ ralé brasileira, Souza não poupa ninguém: dos cânones das ciências sociais ao discurso da grande imprensa, passando pelo mito da brasilidade e o senso comum - pelo qual tem especial interesse. Aos seus olhos, a ideia dominante dos brasileiros sobre si mesmos foi forjada por uma história de dominação simbólica, que poucos conseguiram desvelar adequadamente.

Por isso, em sua avaliação, proceder à crítica das falsas ideias dominantes é a primeira trincheira de luta contra os reais interesses das classes domi- nantes, de modo que seu novo livro pode ser entendido como uma contribuição simultaneamente intelectual e política, dirigida tanto à comunidade acadêmica quanto à população em geral.

De fato, desde o lançamento da primeira edição, em setembro de 2017, o livro tornou-se rapidamente um best-seller de não ficção e o autor expunha suas ideias em diversos meios de comunicação e em eventos públicos, criando verdadeiros flancos de opositores e seguidores. Naquela ocasião, o livro foi logo criticado no jornal Folha de S. Paulo, pelo historiador Thiago Krause (2017), para quem o argumento central do livro induz à dicotomização entre corrupção e desigualdade; o que, ao fim e ao cabo, levaria Souza a defender a interrupção da Operação Lava Jato. Pouco tempo depois, outra crítica foi publicada por Ruy Braga (2017), acusando Souza de desprezar a capacidade de mobilização política das classes populares em lutas sociais específicas, além de apontar confusóes teóricas quanto ao uso do conceito de populismo e abuso de generalizaçóes simplificadas, que, de certa forma, escondem os constantes movimentos de resistência cotidiana da chamada "ralé de novos escravos".

Por que, então, resenhar a segunda edição deste best-seller, se a argumentação central da obra parece já bastante conhecida? Em que medida as análises e provocaçóes de Jessé Souza, materializadas neste livro, são importantes para refletirmos criticamente sobre nosso passado, presente e possibilidades de futuro? Trata-se realmente de uma perspectiva inédita e demolidora, ou apenas de uma eloquente promessa de crítica social?

Para responder a essas questóes, proponho uma leitura contextualizada do livro de Souza. Considero fundamental situar $A$ elite do atraso dentro do conjunto de produçóes do autor, pois alguns conceitos utilizados foram se modificando ao longo do tempo - tais como, o uso das categorias racismo e habitus -, ainda que o novo livro apresente poucas inovações teóricas em relação aos textos precedentes. Provavelmente, a característica mais relevante reside no seu caráter político, enquanto instrumento de difusão de uma leitura historicamente informada da conjuntura recente brasileira. Afinal, na opiniâo de Souza, a atual crise brasileira é fundamentalmente uma "crise de ideias" e, portanto, seu 
interesse declarado, há algum tempo, "é forjar uma compreensão alternativa da realidade brasileira que permita uma intervenção prática na realidade também distinta de tudo que tivemos... [pois] sem novas ideias não existe prática política nova” (Souza, 2016, p. 17).

Convém fazer mais uma observação: existem muitas maneiras de se ler um livro, principalmente quando o contextualizamos no conjunto de escritos de um autor. Por um lado, pode-se ler $A$ elite do atraso como um primeiro contato com o pensamento de Jessé Souza; por outro lado, o livro pode ser objeto de aprofundamento de estudos para quem já teve contato com seus escritos anteriores. Penso que, no primeiro caso, o estilo de escrita e a forma pouco ortodoxa como os argumentos são apresentados podem levar o leitor ou leitora a desvalorizar e desacreditar a obra e seu autor; se assim for, recomendo que sejam lidos também alguns dos trabalhos teóricos e empíricos precedentes (Souza, 2000, 2003, 2009, 2010). No segundo caso, de aprofundamento da leitura, pode ser que o leitor ou leitora já familiarizados com os trabalhos de Souza desapontem-se com o excesso de repetiçôes e a pouca novidade em termos conceituais; sugiro, então, assumir o caráter polêmico do livro como uma tentativa de difusão pública centrada na construção de uma nova narrativa política sobre a realidade social brasileira (Souza, 2015, 2016). À luz dessa leitura qualificada de $A$ elite do atraso, certamente todas as críticas serão muito proveitosas $\mathrm{e}$ esclarecedoras.

Quanto à estrutura, o livro está dividido em um prefácio e quatro capítulos, sendo o primeiro deles, introdutório. Nesta segunda edição revisada, foi incluído um posfácio que estende os argumentos do livro ao período mais recente, especialmente em relação ao processo eleitoral de 2018 e à ascensão neofacista no Brasil. Vejamos como Souza desenvolve seu raciocínio nesta obra.

No prefácio, Souza explica seu objetivo de apresentar uma "resposta crítica" ao clássico Raizes do Brasil, de Sérgio Buarque de Holanda, pois entende que a grandeza deste texto está no fato de ele ter se tornado, desde a sua publicação, em 1936, a leitura dominante - e equivocada - do Brasil, tanto para intelectuais (de esquerda e de direita), quan- to para o senso comum. Este enorme feito deve-se, segundo Souza, ao fato de Buarque ter construído uma narrativa totalizadora, que articula de modo convincente as três questôes fundamentais de qualquer sociedade sobre si mesma: De onde viemos? Quem somos? Para onde (provavelmente) vamos? Para Souza, Sérgio Buarque conseguiu assim criar a legitimação perfeita da dominação social, "com aparência de estar fazendo crítica social” (p. 9). Em relação às críticas anteriores de Souza às obras dos grandes intérpretes do Brasil, a novidade de $A$ elite do atraso reside em oferecer uma reconstrução histórica vinculada ao diagnóstico do presente; isto é, compreender a escravidão como um conceito histórico, cujas consequências são a melhor maneira de explicar a desigualdade persistente e a atual conjuntura política do país.

$\mathrm{Na}$ Introdução, intitulada "O racismo de nossos intelectuais: o brasileiro como vira-lata”, são apresentadas as premissas básicas que nortearão todo o desenvolvimento argumentativo do livro: a "verdadeira corrupção" da "elite do dinheiro" é legitimada e tornada invisível por uma leitura superficial e distorcida da sociedade brasileira, que identifica nosso "mal de origem" no suposto patrimonialismo e corrupção do Estado, herdados de Portugal. Para Souza, com a grande mídia a seu serviço, a elite do atraso conseguiu capturar nossa inteligência e, mais recentemente, o princípio da igualdade social; sendo a maior expressão disso, a sistemática criminalização dos movimentos e partidos de esquerda - representada, na última década, pela transformação do Partido dos Trabalhadores (PT) em uma espécie de mal absoluto. De fato, a maior plataforma eleitoral de 2018 foi o rechaço ao PT.

Em termos epistemológicos, Souza ressalta a passagem - nas ciências sociais, a partir da segunda década do século passado - do paradigma "racista" para o "culturalista". O sucesso do paradigma culturalista será criticado por Souza como falsa ruptura com o racismo científico, pois a mudança da classificação diferencial de indivíduos pela "cor da pele” para a análise do "estoque cultural” específico - por exemplo, todos os brasileiros seriam herdeiros culturais da colonização portuguesa - sustenta, implicitamente, uma "separação ontológica entre seres humanos de primeira classe e seres humanos de 
segunda classe” (p. 19). Nesse ponto, mesmo que com certo avanço analítico em relação a seus trabalhos anteriores, Souza parece continuar desconsiderando o racismo enquanto um sistema específico de dominação, que permanece paralelamente à desigualdade de classes.

Para o autor, a virada culturalista na ciência social brasileira começa com Gilberto Freyre - considerado por Souza "o brasileiro mais genial na esfera do pensamento" (p. 28) -, para quem a identidade do brasileiro remonta à emotividade singular da cultura portuguesa. Na leitura de Souza, Sérgio Buarque utilizou as ideias fundamentais de Freyre para construir uma crítica do brasileiro como "homem cordial" isto é, um tipo de sujeito guiado pelas emoçôes, antes que pela razão -, para quem o patrimonialismo é o traço político definidor da apropriação pessoal do Estado. Esta definição, assentada na negatividade do tipo impetuoso postulado por Freyre, é considerada por Souza uma regressão interpretativa, uma verdadeira celebração de nossa versão "vira-lata" e submissa, perante um suposto sujeito norte-americano ou europeu idealizados. Ainda mais: Sérgio Buarque teria feito escola ao fundamentar ideias conservadoras, como, por exemplo, o "jeitinho brasileiro" analisado por Roberto DaMatta.

Sem muita cerimônia, Souza afirma que o "culturalismo racista e liberal conservador é a única teoria explicativa abrangente e totalizadora que o Brasil possui e que, antes de meu próprio trabalho crítico, jamais havia sido efetivamente criticada nos seus pressupostos fundamentais" (p. 35). Tal perspectiva servirá, ao longo do livro, para tentar estabelecer as bases de uma nova narrativa sobre a sociedade brasileira, fundamentadas na reconstrução da origem das classes dominantes, como resultado das relaçóes de poder sistematicamente legitimadas por um conjunto de ideias falsas, desde a escravidão.

O primeiro capítulo, intitulado "A escravidão é nosso berço", tem início com a explicitação sobre a proposta política do livro: "dotar a esquerda, ou seja, a visão que expressa os interesses da maioria esquecida, de uma reflexão que supere a mera proposição de um programa econômico alternativo, que tem sido o que as esquerdas apresentam quando chegam ao poder" (p. 39). Para tanto, o procedimento metodológico de Souza consiste em re- construir, passo a passo, a obra de Gilberto Freyre, utilizando seus próprios desenvolvimentos teóricos mais recentes acerca da gênese das classes sociais. Isso permitirá evidenciar uma "leitura reprimida" da obra de Freyre, ancorada em uma chave analítica "social-psicológica", na qual o conceito psicanalítico de sadomasoquismo ocupa lugar de destaque. As categorias clássicas de interpretação do período colonial, tais como patriarcalismo, familismo e patrimonialismo - todas supostamente ancoradas no componente culturalista atávico -, passam a ser consideradas como resultantes de uma patologia social específica, cujo cerne estaria em uma sociedade constitutiva e estruturalmente sadomasoquista. Nesse sentido, "a dor alheia, o não reconhecimento da alteridade e a perversão do prazer transformam-se em objetivo máximo das relaçóes interpessoais" (p. 51). Este componente opóe-se à ênfase de Freyre no hibridismo racial e cultural, que seria a base para a posterior afirmação de uma suposta "democracia racial" entre nós. Souza faz questão de lembrar que tal hibridismo não significa, de modo algum, igualdade. Pelo contrário, o sadismo como marca constitutiva das relaçóes interpessoais no período colonial - explica a posição do homem branco português, dono de terras e escravos, como um "hiperindivíduo", sádico em relação às mulheres e homens negros e indígenas, mas também em relação às suas próprias mulheres brancas - objeto de reprodução - e a seus filhos, "os seres que mais sofriam e apanhavam depois dos escravos” (p. 54).

Talvez, a principal novidade teórica apresentada por Souza, neste livro, em sua reconstrução histórica das relaçóes de poder, seja a explicação da gênese da classe média, desde o período colonial. Ao analisar as consequências políticas e sociais das tiranias privadas do senhor de terras, Souza enfatiza uma dimensão intrínseca ao conceito de sadomasoquismo: a proximidade. Tal proximidade implica em certo grau de intimidade e bilateralidade, com base nas relações de favor e proteção, cujo resultado tende a ser um complexo sistema de alianças e rivalidades, mediado pela arbitragem do senhor absoluto em seus domínios. Daí as "funçóes de confiança, no controle do trabalho e da caça de escravos fugidos, além de serviços militares em brigas por limites de terra, etc. que seriam melhor exercidas por 
membros da família ampliada do patriarca” (p. 57). Em um cenário de predomínio de mestiços ocupando diversas dessas funçôes, Souza argumenta que seria possível escrever uma "sociologia do agregado" no Brasil, reconstruindo assim a genealogia das classes médias, a partir da análise do processo de transformação das relaçóes de dominação predominantemente pessoais para as formas impessoais, a partir da chegada da família real portuguesa e seus consortes, em 1808. A "nova lógica social”, trazida da Europa pela corte portuguesa, é interpretada por Souza como a gênese do processo de modernização periférica entre nós. Um "verdadeiro Estado transplantado" (p. 62) altera radicalmente o cenário político e econômico anterior, já que a partir de então o senhor de terras perde a plenitude de seus poderes e passa a conhecer um poder coercitivo superior, que o obriga a cumprir com seus compromissos perante o Estado.

Aos estratos intermediários da população, abriu-se uma janela de oportunidade de ascensão pela incorporação de capital cultural socialmente valorizado, sendo decisiva a distinção em relação aos "de baixo". O processo de incorporação do mestiço à nova sociedade ocorreu paralelamente à transformação das relaçóes produtivas e à importação de mão de obra imigrante, principalmente italiana, favorecida pelo aspecto simbólico decisivo da época, que era a demonização do negro e de sua cultura. No trânsito de uma sociedade escravista para o capitalismo competitivo, tudo que fosse associado ao escravo constituía um elemento negativo em relação ao qual todos desejavam se distinguir; daí a afirmação de Souza, de que "o ódio ao pobre hoje em dia é a continuação do ódio devotado ao escravo de antes" (p. 70).

No segundo capítulo, intitulado "As classes sociais do Brasil moderno", temos uma interpretação de nossa desigualdade metodologicamente orientada pela reconstrução da socialização familiar e da incorporaçâo diferencial de disposiçốes de comportamento entre as diferentes classes sociais. Para Souza, existem apenas quatro classes sociais no Brasil: 1) os "endinheirados" da elite do atraso; 2) a classe média e suas fraçóes; 3) a classe trabalhadora socialmente integrada, denominada "batalhadores"; e 4) a classe dos "excluídos" ou "desclassificados so- ciais", provocativamente chamada de "ralé de novos escravos". Um ponto decisivo da argumentação do autor, neste livro, é a análise do topo da pirâmide social. A elite dos endinheirados, representada por $1 \%$ ou menos da população, observa a dominância crescente do capitalismo financeiro e a transformaçấo de grande parte do setor produtivo em rentismo e especulação. Por sua vez, a classe média e suas fraçóes representam um universo mais complexo e contraditório, podendo ser ilustrativamente dividido em quatro nichos ou fraçóes: 1) fração liberal, cerca de 35\% do total; 2) fração protofascista, cerca de 30\%; 3) fração "expressivista", ou "classe média de Oslo", representando 20\%; e 4) a fração crítica, menor em termos quantitativos, representando cerca de $15 \%$ da classe média. Nas duas últimas frações, concentra-se o grau mais elevado de capital cultural; enquanto as duas primeiras representam a classe média tradicional do conhecimento técnico, mais suscetíveis à imprensa tradicional e ao moralismo. A diferença entre as fraçôes "liberal" e "protofascista" reside na assimilação do discurso de ódio e na explícita banalização do mal pelos indivíduos deste segundo grupo.

No terceiro e último capítulo, intitulado "A corrupção real e a corrupção dos tolos”, Souza apresenta um "experimento empírico" e analisa discursos públicos - de Deltan Dallagnol (Procurador do Ministério Público Federal), Luis Roberto Barros (Ministro do Supremo Tribunal Federal) e Fernando Haddad (ex-Prefeito de São Paulo, pelo PT) -, para demonstrar seus argumentos. Ainda que superficial, tal experimento torna-se convincente, na medida em que é precedido por uma digressão teórica apoiada em Max Weber, para então retornar à crítica feita ao pacto antipopular, formado entre a elite do dinheiro e os setores mais conservadores da classe média, mediado pela colonização da esfera pública. Uma das teses mais importantes desenvolvidas neste momento do texto, à guisa de conclusão, é a de que temos vivido um ataque não apenas à democracia, mas ao próprio princípio da igualdade.

Encerrando, Souza utiliza como exemplos o ódio e a violência crescentes, como resultado do conluio entre a grande mídia e os interesses da "elite do atraso". Interesses estes, que se arregimentaram em torno da figura dos Bolsonaros, em relação 
à passividade perante a dívida pública jamais auditada, além de certa perda da capacidade de aprendizado social. Como remédio para tais circunstâncias, Souza propóe o reconhecimento de nossos autoenganos, pois "a conta do ódio aos pobres foi o empobrecimento de todos"; e, por isso, conclama: "feitos de imbecis de todo o país, uni-vos!” (p. 246).

O acréscimo de um posfácio na edição de 2019 confere ao livro um tom ainda mais ativista, ao propor uma análise da recente ascensão neofascista na sociedade brasileira. A mobilização política do ódio, a disseminação de fake news e o discurso de combate à corrupção são denunciados como uma cortina de fumaça, que esconde a "corrupção real" da "elite do atraso". A posição de Souza é explícita: não há oposição real ao fascismo, sem que sejam explicadas as causas da dominação à população dominada. É a isto que ele dedica sua escrita.

A elite do atraso é, certamente, um livro provocativo, ainda que com pouca novidade em seu conteúdo, tendo em vista os textos precedentes do mesmo autor. Escrito numa linguagem direta e coloquial, o livro pretende ser acessível ao público generalizado, e não apenas à academia. Seu mérito maior parece ser formal, na medida em que se propóe a potencializar reflexôes e instigar a tomada de posição. Em suma, se levado a sério e com o respeito devido à trajetória do autor, trata-se de um texto que merece ser lido e criticado. Penso que é por isso que devemos ler Jessé Souza: para fazer avançar o pensamento crítico.

\section{Notas}

1 Publicada em setembro de 2017, como "A elite do atraso: da escravidão à Lava Jato”, pela editora LeYa.
KRAUSE, Thiago. (2017), "No Brasil, desigualdade e corrupção se reforçam mutuamente, diz historiador". Folha de S. Paulo, 20 out. Ilustríssima. Disponível em: https://www1.folha.uol. com.br/ilustrissima/2017/10/1928582-escravismo-do-passado-persiste-e-ajuda-a-explicar-corrupcao-diz-historiador.shtml, consultado em 05/3/2019.

SOUZA, Jessé. (2000), A modernização seletiva: uma reinterpretação do dilema brasileiro. Brasília, Editora UnB.

SOUZA, Jessé. (2003), A construção social da subcidadania: para uma sociologia política da modernidade periférica. Belo Horizonte, Editora UFMG.

SOUZA, Jessé. (2009), A ralé brasileira: quem é e como vive. Belo Horizonte, Editora UFMG.

SOUZA, Jessé. (2010), Os batalhadores brasileiros: nova classe média ou nova classe trabalhadora? Belo Horizonte, Editora UFMG.

SOUZA, Jessé. (2015), A tolice da inteligência brasileira: ou como o país se deixa manipular pela elite. São Paulo, LeYa.

SOUZA, Jessé. (2016), A radiografia do golpe: entenda como e por que você foi enganado. Rio de Janeiro, LeYa.

\section{BIBLIOGRAFIA}

BRAGA, Ruy. (2017), "Pode o subalterno lutar?". Revista Quatro Cinco Um, $01 \mathrm{dez}$. Disponível em https:/www.quatrocincoum.com.br/br/ resenhas/ciencias-sociais/pode-o-subalterno-lutar, consultado em 05/3/2019.

\footnotetext{
(cc) BY Creative Commons License This is an Open Access article distributed under the terms of the Creative Commons Attribution License, which permits unrestricted use, distribution, and reproduction in any medium, provided the original work is properly cited.
} 